Document downloaded from:

http://hdl.handle.net/10251/149970

This paper must be cited as:

Huyen, PT.; Nam, LTH.; Vinh, TQ.; Martínez, C.; Parvulescu, VI. (2018). ZSM-5/SBA-15 versus Al-SBA-15 as supports for the hydrocracking/hydroisomerization of alkanes.

Catalysis Today. 306:121-127. https://doi.org/10.1016/j.cattod.2017.03.040

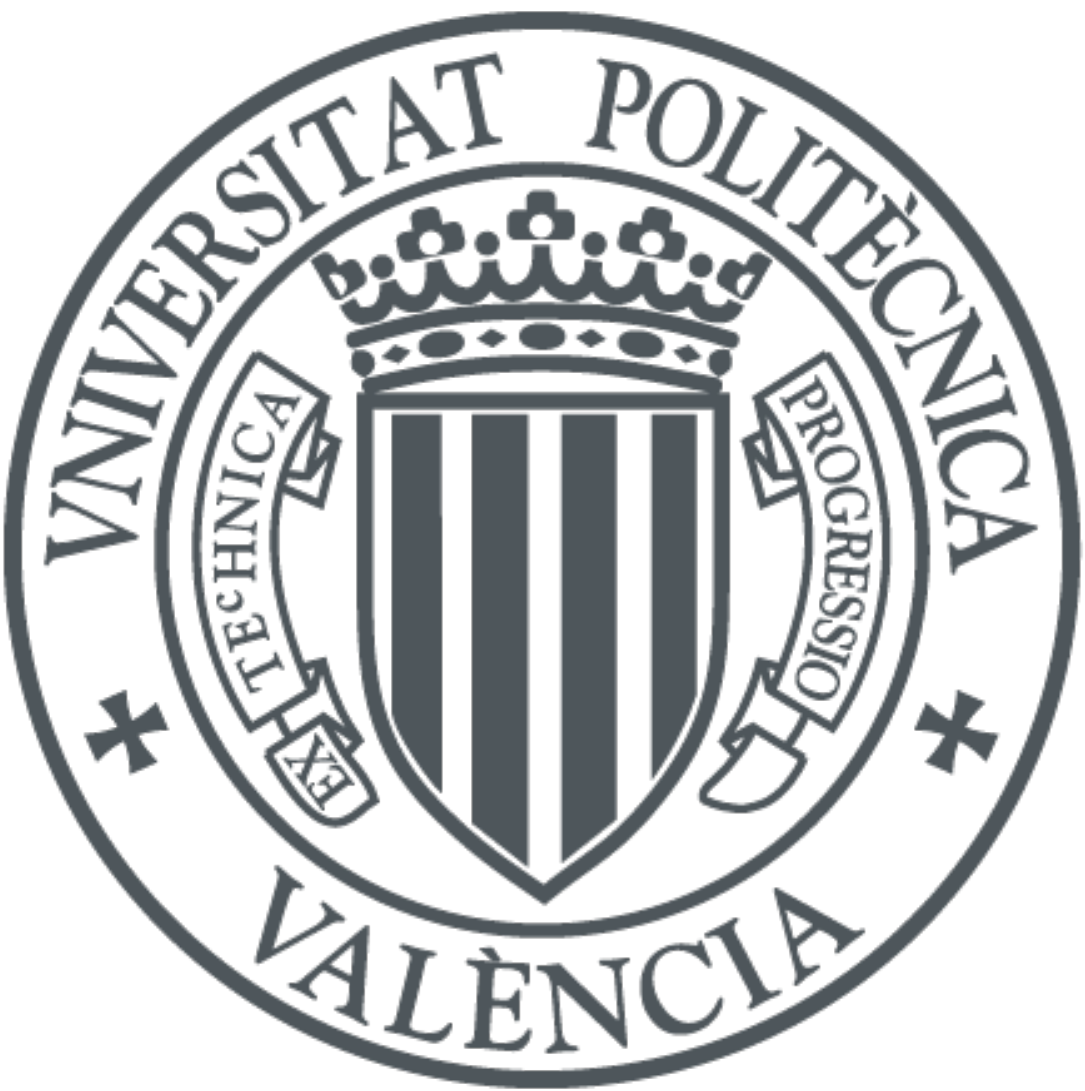

The final publication is available at

https://doi.org/10.1016/j.cattod.2017.03.040

Copyright Elsevier

Additional Information 


\title{
ZSM-5/SBA-15 versus Al-SBA-15 as supports for the hydrocracking/ hydroisomerization of alkanes
}

\author{
Pham T. Huyen ${ }^{1 *}$, Le T. H. Nam², Tran Q. Vinh ${ }^{2}$, Cristina Martínez ${ }^{3 *}$, Vasile I. Parvulescu ${ }^{4 *}$ \\ ${ }^{1 *}$ School of Chemical Engineering, Hanoi University of Science and Technology, 1 Dai \\ Co Viet, Hanoi,Vietnam, E-mail: huyen.phamthanh@hust.edu.vn \\ ${ }^{2}$ Institute of Chemistry, Vietnam Academy of Science and Technology, Vietnam \\ ${ }^{3}$ Instituto de Tecnología Química, Universitat Politècnica de València - Consejo Superior \\ de Investigaciones Científicas, Spain \\ ${ }^{4}$ Department of Organic Chemistry, Biochemistry and Catalysis, University of Bucharest, \\ Romania, Email: vasile.parvulescu@chimie.unibuc.ro
}

\begin{abstract}
Al-SBA-15 and ZSM-5/SBA-15 (ZSC) composite were synthesized following hydrothermal procedures in the presence of triblock copolymer Poly(ethylene glycol)poly(propylene glycol)-poly(ethylene glycol) (Pluronic P123) and a mixture of tetrapropylammonium bromide (TPABr)/Pluronic P123 templates, respectively. $\mathrm{Pt}(0.5 \mathrm{wt} . \%) / \mathrm{Al}-\mathrm{SBA}-15$ and ZSC bifunctional catalysts were then prepared by a wet impregnation methodology and investigated in the hydrocracking/hydroisomerization of $n$ decane. Pt/ZSC, containing a trimodal porous texture and high Brønsted acidity, exhibited hydrocracking activity while Pt/Al-SBA-15, showing merely Lewis acidity, was active for hydroisomerization. At $300^{\circ} \mathrm{C}$ the conversion of $n$-decane on Pt/ZSC reached $98 \%$ and cracking selectivity was about $99 \%$. Both catalysts were exhaustively characterized.
\end{abstract}


Keywords: ZSM-5/SBA-15 composite, Pt(0.5wt.\%)/Al-SBA-15 and Pt(0.5wt.\%)/ZSM5/SBA-15 catalysts, hydrocracking and hydroisomerization of $n$-decane

\section{Introduction}

Despite the increasing importance of energy and fuel sources alternative to oil, there is a large dependency of both sectors on this fossil source, and, therefore, nowadays there is a constant need for the conventional refinery process optimization and the efficiency increase. However, the oil reserves are being depleted and, therefore, the refineries which are using light crude oils (such as Binh Son refinery, Vietnam) will have to seek new feedstocks of heavy crude oil in the near fulture. Heavy crude oil are more difficult to convert, due to their higher $\mathrm{C} / \mathrm{H}$ molar ratio and the presence of heteroatoms such as sulfur, nitrogen or heavy metals $(\mathrm{Ni}, \mathrm{V})$, which may end up in the products obtained, decreasing their quality, or on the catalyst, decreasing its activity. The two main conversion processes are fluid catalytic cracking (FCC) and hydrocracking [1]. The latter presents a significant advantage over FCC, as it combines the cracking reactions with removal of the heteroatoms, especially sulfur, from the hydrocracked product streams.

The catalysts for hydrocracking/hydroisomerization of $\mathrm{n}$-alkanes are bifunctional and contain acid and metal sites which have to be equilibrated and in close proximity in order to enhance the $\mathrm{C}-\mathrm{C}$ bond breaking and hydrogenation of the unsaturated produced during the cracking [2-5]. The reaction mechanism and the influence of hydrogenation activity and molecular weight of the $\mathrm{n}$-alkane on the final product distribution was already described in the early 1960's by Coonradt and Garwood [Coonradt, H.L. and Garwood, W.E., Ind. Eng. Chem. Process Res. Dev. 3(1) (1964) 38-45], and later reviewed by others 
[Martens, J.A. and Jacobs, P.A., Zeolites 6 (1986) 334-348; ] ADD MORE REFERENCES AND SOME COMMENTS.

The acidity of the catalyst has a major influence on both the hydroisomerization and hydrocracking yields. The acid site density and acid strength distribution are both important and the proper balance of these variables is critical in determining the reactivity and selectivity of the bifunctional catalysts [6, 7]. ADD MORE REFERENCES AND

\section{SOME COMMENTS}

Besides the metal site and the acidity, other characteristics of the supports, such as the pore size distribution or surface area, represent important elements controlling the bifunctional catalyst performances [8] ADD MORE REFERENCES AND SOME COMMENTS. To date, many supports with various pore sizes and different acidity, such as microporous [9 - 14], mesoporous [2, 15] or mixtures of micro-mesoporous [6, 8] materials have already been reported. Among these, On and Kaliaguine [16] reported the successful synthesis of materials presenting semi-crystalline zeolitic mesoporous walls. This kind of multimodal porous materials combines some advantages of micro- and mesoporous materials such as hydrothermal stability, high acidity, crystalline structure with the presence of well-defined micropores and ordered mesoporous structure, and a high surface area [17].

Based on this state of the art, the aim of this study was to investigate the behavior of a SBA-15 modified by Al and a composite of SBA-15 with ZSM-5 (noted as ZSC) taking as reaction model the hydrocracking of $n$-decane. Using such supports it was investigated both the effect of acidity and the support pore size.

\section{Experimental}




\section{Catalysts synthesis}

A ZSM-5/SBA-15 composite (ZSC) was synthesized according to an already reported procedure by Nam et al [17]. The samples were synthesized via three steps. In the step 1, seed 1 was synthesized from a homogeneous gel solution of $12.84 \mathrm{~g}$ Ludox AS-40, $0.71 \mathrm{~g}$ $\mathrm{Al}_{2}\left(\mathrm{SO}_{4}\right)_{3} .18 \mathrm{H}_{2} \mathrm{O}$ dissolved in $55 \mathrm{~mL} \mathrm{H}_{2} \mathrm{SO}_{4} 0.45 \mathrm{M}$ and $1 \mathrm{~g}$ tetrapropylammonium bromide (TPABr) dissolved in $4 \mathrm{~mL} \mathrm{H}_{2} \mathrm{O}$. The resulting gel was aged for $24 \mathrm{~h}$ and crystallized at $170^{\circ} \mathrm{C}$ for $8 \mathrm{~h}$ while stirring. Before the composite material formation step, seed 1 was added with $3.77 \mathrm{~g}$ Ludox AS-40 precursor in the step 2. The mixture was hydrothermally treated at $100^{\circ} \mathrm{C}$ for $6 \mathrm{~h}$ while stirring to form seed 2 . The synthesis of the mesoporous material, in step 3, was performed by adding the mixture obtained from the step 2 to a solution of $3 \mathrm{~g}$ Pluronic (P123) dissolved in $80 \mathrm{~mL} \mathrm{H}_{2} \mathrm{SO}_{4} 1.52 \mathrm{M}$. The resulting mixture was hydrothermally treated at $90^{\circ} \mathrm{C}$ for $24 \mathrm{~h}$. The solid product was filtered and washed using deionised water to $\mathrm{pH}=7$, dried at $100^{\circ} \mathrm{C}$, and calcined at $550^{\circ} \mathrm{C}$ for $5 \mathrm{~h}$ to remove the TPABr and $\mathrm{P} 123$ templates.

Al-SBA-15 was synthesized from 3.5 grams of P123 dissolved in $100 \mathrm{~mL}$ of $1.5 \mathrm{M} \mathrm{HCl}$ under vigorous stirring. After that, $0.6 \mathrm{~g}$ of aluminum sulfate were added and the solution was stirred for another hour. Then, $8.5 \mathrm{~g}$ of TEOS were gradually dropped and the solution was maintained at room temperature for $15 \mathrm{~h}$, and at $40{ }^{\circ} \mathrm{C}$ for another $24 \mathrm{~h}$. The obtained suspension was crystallized at $90{ }^{\circ} \mathrm{C}$ for $48 \mathrm{~h}$ in an autoclave. Then the solid product was filtered, washed with double distilled water, dried and calcined at $550{ }^{\circ} \mathrm{C}$ for $6 \mathrm{~h}$ (heating rate of $1{ }^{\circ} \mathrm{C} \mathrm{min}^{-1}$ ). SBA-15 was prepared following the same procedure as for Al-SBA-15 but without adding aluminum sulfate. 
The deposition of $\mathrm{Pt}(0.5 \mathrm{wt} . \%)$ on these supports was carried out by a wet impregnation methodology as described in a previous paper [18].

\section{Catalysts characterization}

The $\mathrm{N}_{2}$ adsorption-desorption isotherms were recorded at $-196{ }^{\circ} \mathrm{C}$ using a Micromeritics ASAP2020 automated instrument. Prior to analysis, the catalysts containing Pt were pretreated in a $\mathrm{H}_{2}$ flow $\left(300 \mathrm{~mL} \mathrm{~min}{ }^{-1}\right)$ at $400{ }^{\circ} \mathrm{C}$ for $2 \mathrm{~h}$ with a heating rate of $0.5{ }^{\circ} \mathrm{C} \mathrm{min}{ }^{-1}$, then cooled in $\mathrm{H}_{2}$, exposed to argon $\left(30 \mathrm{~mL} \mathrm{~min}^{-1}\right)$ for $30 \mathrm{~min}$, and then degassed for $15 \mathrm{~h}$ at $150^{\circ} \mathrm{C}$ and $1.3 \times 10^{-9}$ atm. Surface areas were estimated according to both the Langmuir and BET models, and the pore sizes were calculated using the micropore and BJH methods.

Powder X-ray diffraction patterns were recorded with a Phillips PW 1830 diffractometer using the $\mathrm{CuK} \alpha$ radiation. Small and Wide angle XRD patterns were collected in steps of $0.02^{\circ}(2 \theta)$ over the angular ranges $(2 \theta)$ of $0.5-10^{\circ}(\mathrm{SXRD})$ or $5-45^{\circ}(\mathrm{WXRD})$ for $25 \mathrm{~s}$ per step.

The Pyridine-(Py) FTIR spectra were recorded with a IMPACT-410 (Germany) Infrared Spectrophotometer, with a resolution of $4 \mathrm{~cm}^{-1}$. Prior to the adsorption the base, the powder samples were calcined at $450{ }^{\circ} \mathrm{C}$ for $2 \mathrm{~h}$ under a flow of air $\left(30 \mathrm{~mL} \mathrm{~min} \mathrm{~m}^{-1}\right)$. Selfsupporting wafers obtained by compression (about $12 \mathrm{mg} \mathrm{cm}^{-2}$ ) were outgassed in the IR cell at $400^{\circ} \mathrm{C}$ at a residual pressure of $1 \mathrm{~atm}$. After the adsorption of Py, the samples were purged for $2 \mathrm{~h}$ with $\mathrm{He}\left(30 \mathrm{~mL} \mathrm{~min} \mathrm{~m}^{-1}\right)$ at $\mathrm{RT}$ to remove the weakly sorbed species, and then heated at $150{ }^{\circ} \mathrm{C}$. 
Transmission electron microscopy (TEM) analyses were performed with a JEOL JEM1010 microscope at an accelerating voltage of $100 \mathrm{kV}$. Samples were prepared by powder dispersion in ethanol and subsequent deposition on a gold grid with carbon support.

\section{Catalytic activity test}

All the experiments were carried out in a fixed bed stainless steel reactor, using $0.3 \mathrm{~g}$ catalyst with particle size of 0.2-0.4 mm. The catalyst was in-situ pre-reduced in hydrogen $\left(300 \mathrm{~mL} \mathrm{~min}^{-1}\right)$ at $400^{\circ} \mathrm{C}$ for $2 \mathrm{~h} . n$-decane $\left(1.56 \mathrm{~g} \mathrm{~h}^{-1}\right)$ was fed by means of a high pressure piston type pump. The reaction conditions corresponded to a $\mathrm{H}_{2} /$ substrate molar ratio of 9/1 or $18 / 1$, pressure of 40 bars, temperatures in the range of $250-350^{\circ} \mathrm{C}$, and WHSV of $5.1 \mathrm{~h}^{-1}$. The analysis of the gas and liquid products was carried out with a GC Varian STAR 3400 equipped with TCD and FID detectors using a FACTOR FOUR VF-1 MS column.

\section{Results and discussion}

\section{Textural characterization}

Figure 1 and Table 1 present the textural characteristics of the investigated catalysts.
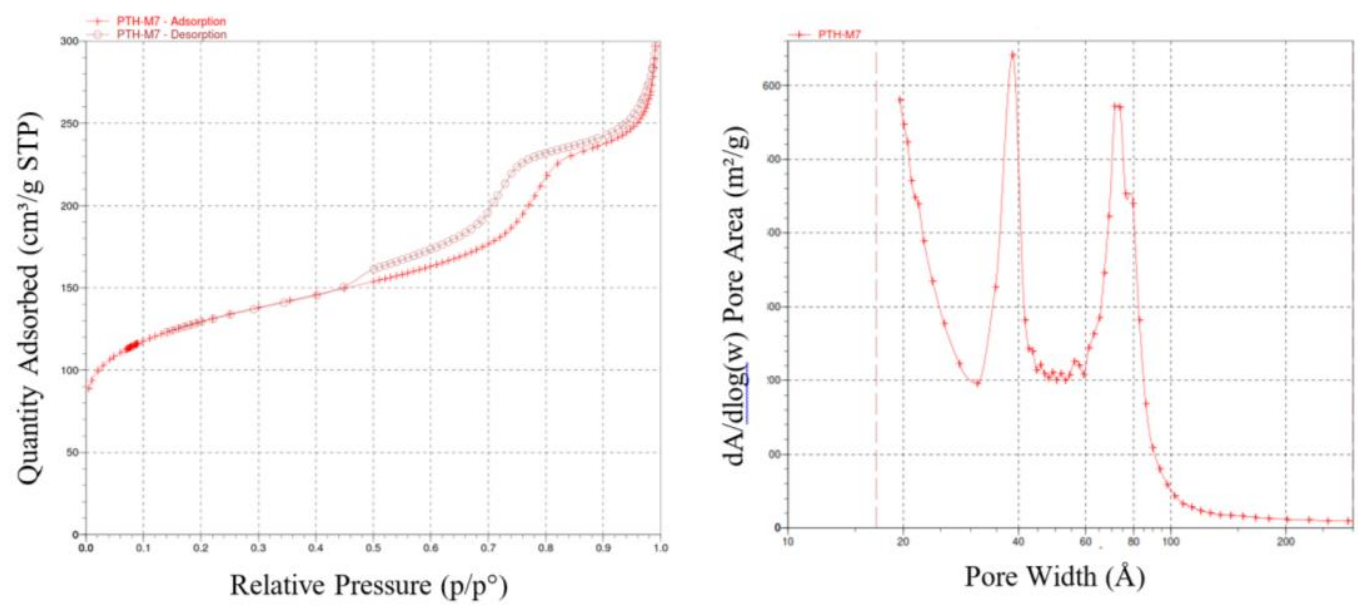

Figure 1. $\mathrm{N}_{2}$ Isotherms and mesopore size distribution of Pt/ZSC 
As expected, both BET and micropore surface areas of Pt/ZSC and Pt/Al-SBA-15 were smaller than those of the parent supports. In addition, for Pt/Al-SBA-15 the pore size distribution changed to bimodal with mesopores of 39 and $62 \AA$ [18]. For the ZSC support, the micropore surface area was nearly half of the BET surface. However, after the deposition of $\mathrm{Pt}$, the diminution of the surface occurred merely in the mesopore range, and micropore surface increases (see Table 1). It would be possible that the wet impregnation for Pt incorporation (performed in an aqueous solution) could wash out some amourphous debris, cleaning in this way part of the micropores, or part of mesopores being transformed in micropores. As can be seen in Table 1, there is a good agreement of the target and real Pt content in both catalysts.

Table 1. Textural characteristics of Pt/ZSC and Pt/Al-SBA-15 catalysts

\begin{tabular}{|c|c|c|c|c|c|c|}
\hline Sample & $\begin{array}{c}\text { BET } \\
\text { surface }\end{array}$ & $\begin{array}{c}t \text {-plot } \\
\text { micropore }\end{array}$ & $\begin{array}{c}\text { Pore } \\
\text { volume }\end{array}$ & $\begin{array}{l}\text { Pore } \\
\text { size }\end{array}$ & $\begin{array}{c}\mathrm{Si} / \mathrm{Al} \\
\text { (ICP result) }\end{array}$ & $\begin{array}{c}\mathrm{Pt} \\
(\mathrm{ICP}\end{array}$ \\
\hline & area & surface area & & & & result) \\
\hline & $m^{2} g^{-1}$ & $m^{2} g^{-1}$ & $\mathrm{~cm}^{3} \mathrm{~g}^{-1}$ & $\AA$ & & wt.\% \\
\hline $\mathrm{ZSC}$ & 541 & 254 & 0.51 & 40,75 & 51.01 & - \\
\hline $\mathrm{Pt} / \mathrm{ZSC}$ & 437 & 280 & 0.45 & 39,72 & 50.77 & 0.49 \\
\hline Al-SBA-15 & 697 & 289 & 1.04 & 90 & 28.96 & - \\
\hline Pt-Al-SBA-15 & 684 & 255 & 0.79 & 39,62 & 27.63 & 0.51 \\
\hline
\end{tabular}

XRD characterization

The SXRD and WXRD patterns of the supports and catalysts are shown in Figure 2. The presence of platinum was not detected in the XRD patterns of both catalysts that can be 
explained by the existence of highly dispersed small metal particles [18]. These diffractograms also confirmed the well-defined pattern of ZSM-5 in both the Pt free and Pt containing samples. For ZSC, the addition of Pt led to a decrease of the pore size (as also seen from the textural characterization).
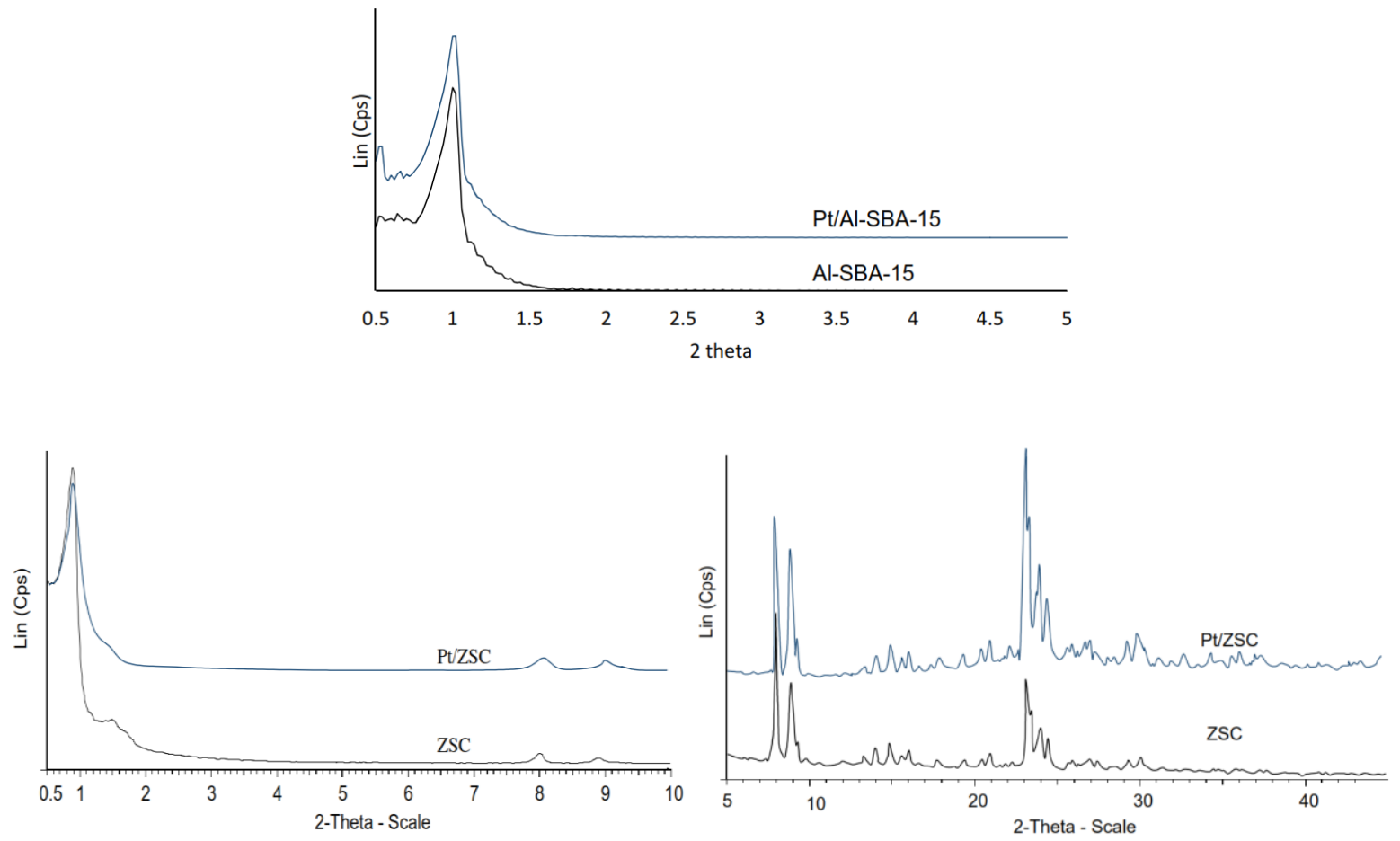

Figure 2. XRD patterns of Al-SBA-15, ZSC (small angle and wide angle) and supported Pt catalysts

\section{TEM measurements}

TEM pictures of the investigated catalysts are presented in Figure 3. They show a better dispersion of platinum on Al-SBA-15 than ZSM-5/SBA-15 composite support (Figure 3) that may also explain the differences in the measured surface areas (See Table 1). The ordered mesoporous structure of SBA-15 is not very clear in the TEM of ZSC that might 
be explained by the presence of embedded small ZSM-5 crystallites in the amorphous walls of SBA-15. Such a behavior results in a semicrystalline wall structure, so that the walls are less defined than in the Al-SBA-15.

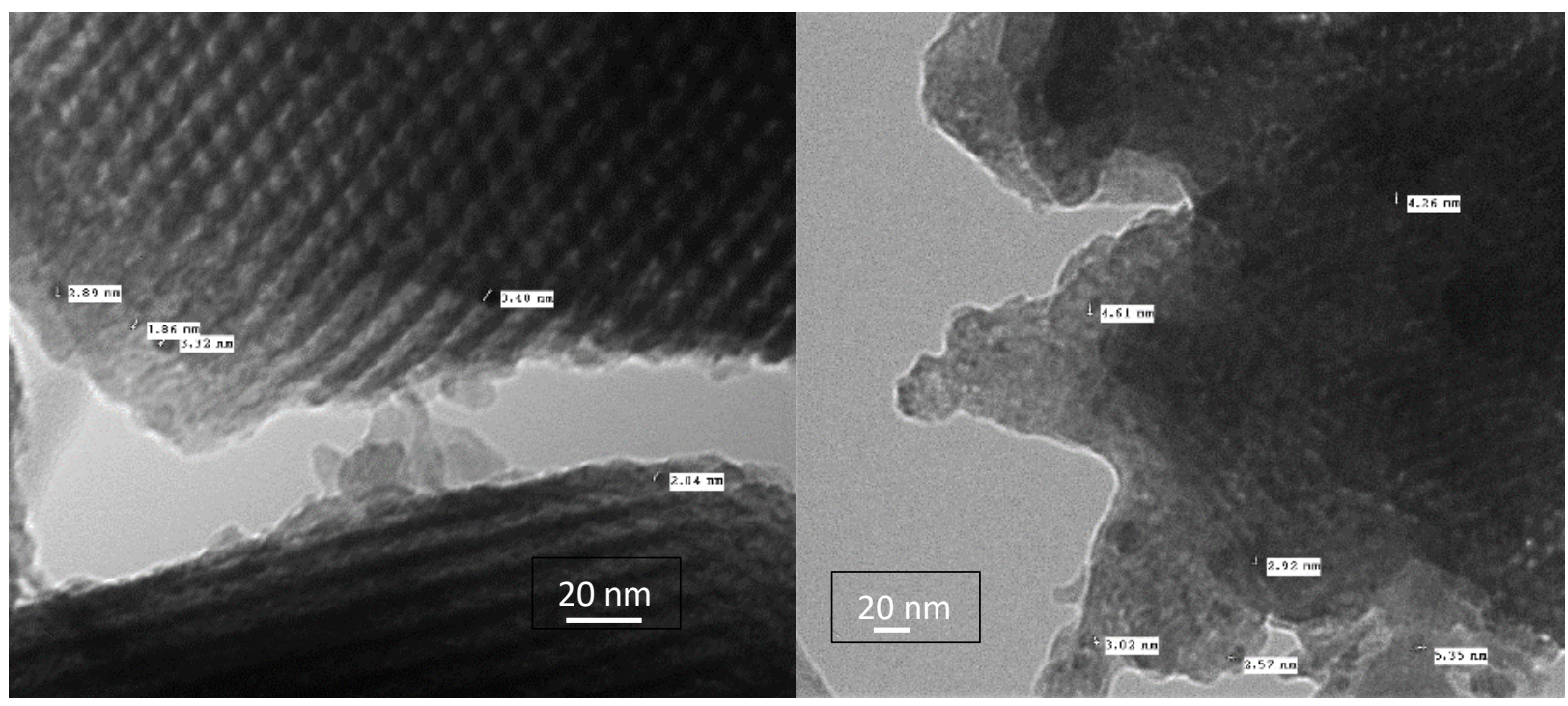

Figure 3. TEM pictures of Pt/Al-SBA-15 (left) and Pt/ZSC (right)

The Py-FTIR spectra of Pt/ZSC catalysts compared to those of Pt/SBA-15 and Pt/Al-SBA15 are shown in Figure 4.

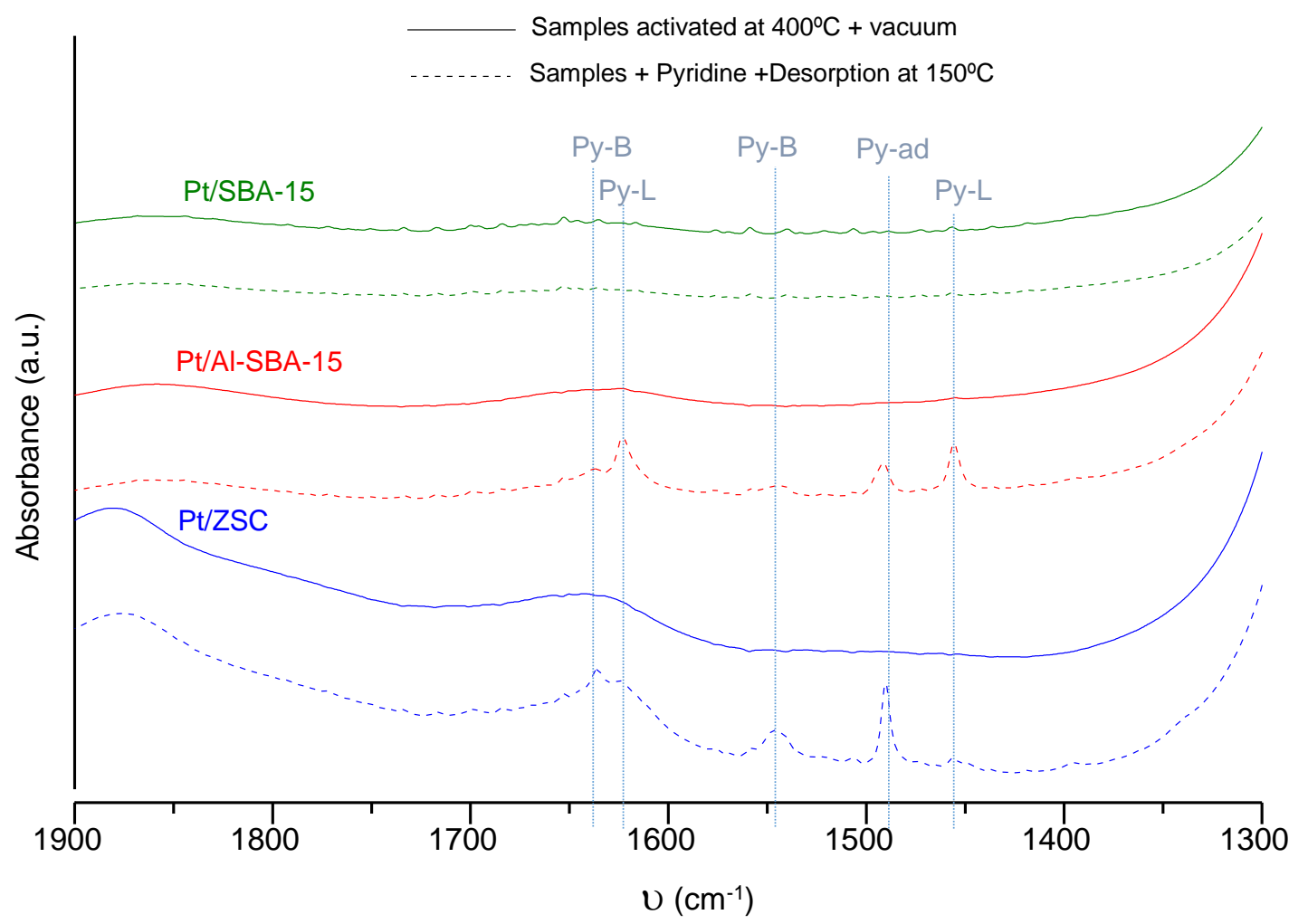


Figure 4. Py-FTIR spectra of Pt/ZSC catalysts compared to Pt/SBA-15 and Pt/Al-SBA-15

They indicate that Pt/SBA-15 exhibits no acidity (no pyridine adsorption has been detected on this catalyst). For the Pt/ZSC and Pt/Al-SBA-15 catalysts the Py-FTIR spectra evidence the presence of the acidity. The bands at 1622 and $1453 \mathrm{~cm}^{-1}$ account to the vibration modes of pyridine adsorbed on Lewis site (Py-L) $[2,18]$, and the absorption bands at 1636 and $1540 \mathrm{~cm}^{-1}$ were assigned to the basic probe interacting with Brønsted acid sites (Py-B). Pyridine adsorbed (Py-ad) on either Lewis or Brønsted sites can be seen at $1490 \mathrm{~cm}^{-1}$. Although not quantified, these spectra suggest that the population of the Lewis acid sites on Pt/Al-SBA-15 is much higher than that on Pt/ZSC catalyst, whereas the Brønsted acid site density in Pt/ZSC is larger than that on Pt/Al-SBA-15. The higher Lewis acidity and lower Brønsted acidity of Pt/Al-SBA-15 as compared to Pt/ZSC might be due to the lower Si/Al ratio of Pt/Al-SBA-15 (27.6) compared to that of Pt/ZSC (50.8) that corresponds to a larger population of Lewis sites on Pt/Al-SBA-15. On other hands, it is more due to the amorphous nature of this material and its lower stability. It has been described that during Pt incorporation in aqueous media the Brønsted acid sites in AlSBA-15 are converted into strong Lewis sites [19]. These results also confirm the fact that the modification of SBA- 15 by Al and ZSM-5 increased the acidity of the catalysts.

\section{Catalytic behavior}

The first aspect to be noted is that Pt/SBA-15 exhibited no hydrocracking activity that is in concordance to the absence of the acidity (results not shown).

Figure 5 shows the influence of the reaction temperature and support on the hydrocraking of $n$-decane onto Pt/ZSC and Pt/Al-SBA-15 catalysts. The chromatographic analysis 
including the distribution of the reaction products for $n$-decane hydrocracking on Pt/ZSC and Pt/Al-SBA-15 catalysts is compiled in the Tables 2 and 3, respectively.
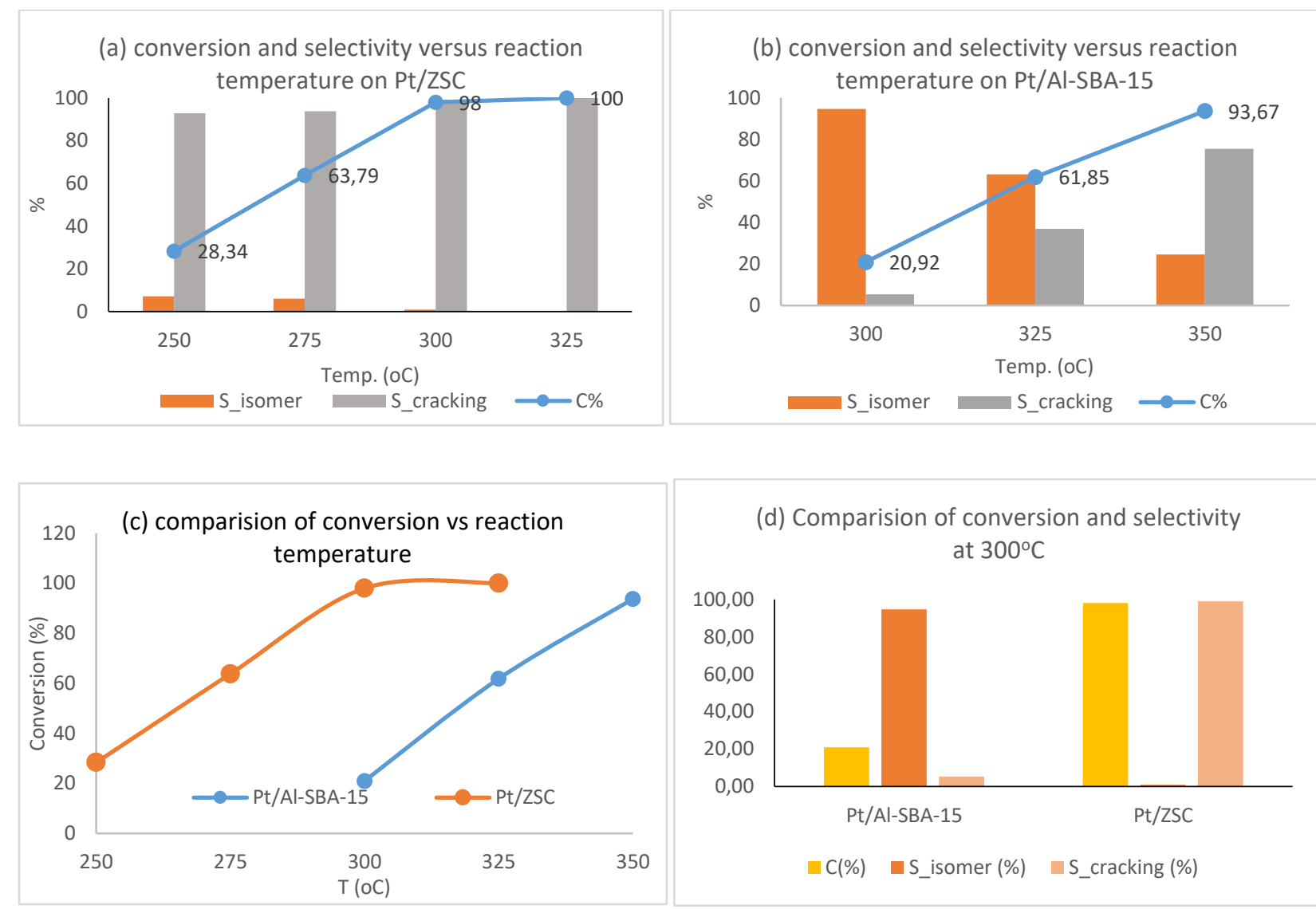

(d) Comparision of conversion and selectivity at $300^{\circ} \mathrm{C}$
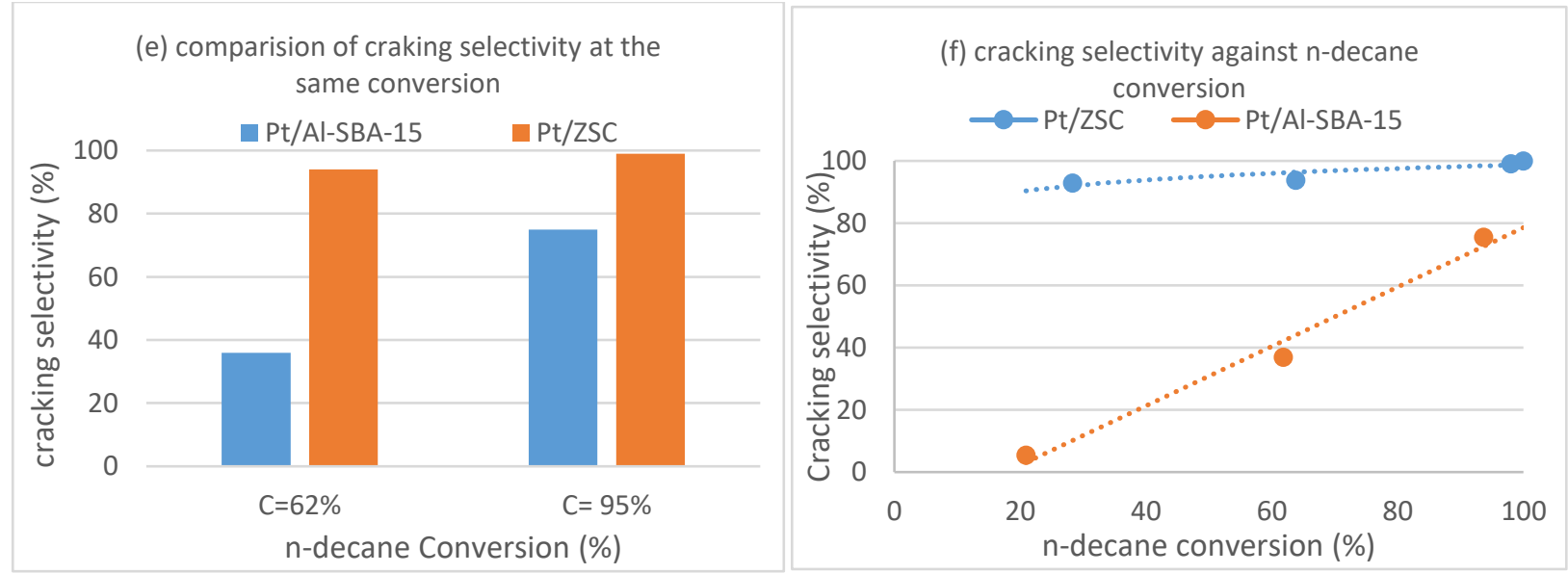

Fig.5. Influence of temperature and supports for the $n$-decane

hydrocracking/hydroisomerization: a, b) conversion and selectivity versus reaction

temperature on Pt/ZSC and Pt/Al-SBA-15; c) comparision of conversion vs reaction temperature on Pt/ZSC and Pt/Al-SBA-15; d) comparision of conversion and selectivity at 
$300^{\circ} \mathrm{C}$; e) comparision of craking selectivity at the same conversion; f) cracking selectivity against $\mathrm{n}$-decane conversion. (WHSV $=5.2 \mathrm{~h}^{-1}, \mathrm{H}_{2} / \mathrm{n}-\mathrm{C} 10=9, \mathrm{P}=40 \mathrm{bar}$ )

$\mathrm{Pt} / \mathrm{ZSC}$ showed high catalytic activity for the hydrocracking. At $300^{\circ} \mathrm{C}$, the conversion of $n$-decane reached $98 \%$ with a cracking selectivity of about $99 \%$ on Pt/ZSC, whereas the conversion of $n$-decane was only $20.92 \%$ and cracking selectivity was only $5.37 \%$ on Pt/Al-SBA-15.

For Pt/Al-SBA-15 conversions of around $\sim 93 \%$ were obtained at higher temperature $\left(350^{\circ} \mathrm{C}\right)$, and with a much smaller cracking selectivity $(\sim 75 \%)$. Compared to Al-SBA-15, the ZSC composite preserved a superior selectivity to cracking independently of the conversion at which they were evaluated. In both cases, hydrocracking is dominating at high conversions [20].

The analysis of the results presented in Tables 2 and 3 also shows that while Pt/ZSC (which contains both miro- and mesopores) favored the hydrocracking reaction, Pt-Al-SBA-15 stimulated the isomerization one. Thus, Pt-Al-SBA-15 led to the highest isomerization selectivity $\left(94.6 \%\right.$ at $\left.300^{\circ} \mathrm{C}\right)$ for a $n$-decane conversion of $20.9 \%$

Isomerization and hydrocracking of an n-alkane occur on bi-functional catalysts following the classical mechanism involving the formation of an alkylcarbenium ion. Accordingly, the alkane is firstly dehydrogenated onto the metal site to alkene, which is then protonated by a Brønsted acid site to form an alkylcarbenium ion [7, 12]. Pt/ZSC presented a multimodal porous structure and higher Brønsted acidity. These characteristics may explain the hydrocracking capability of this catalyst comparing to hydroisomerization. Figure 6 depicts the reaction pathway on the investigated catalysts. 


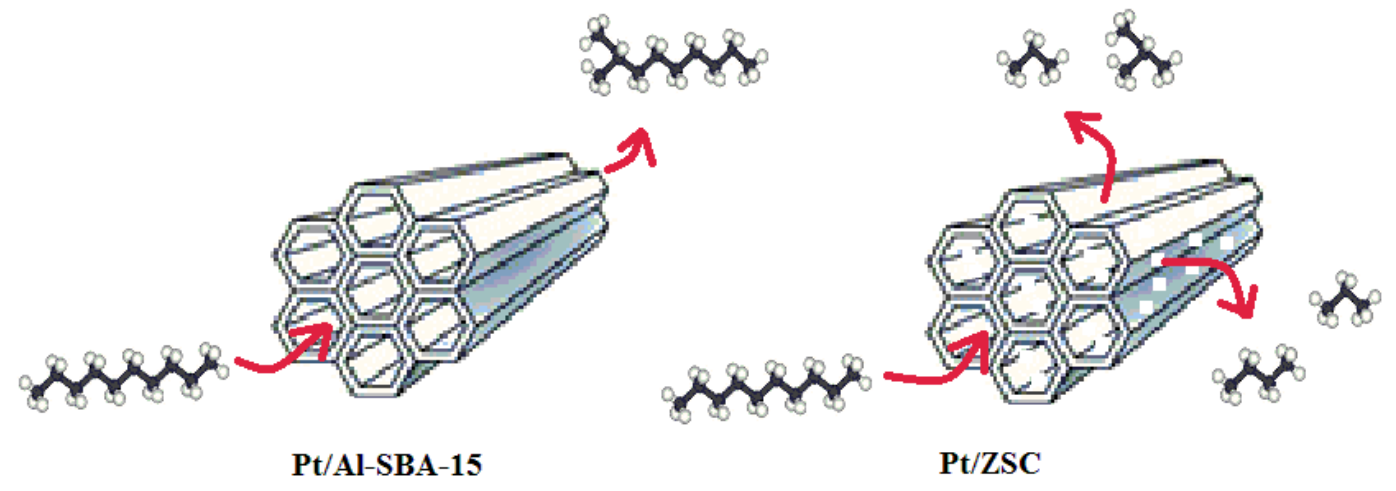

Fig.6. Reaction pathway for the hydroisomerization/hydrocracking of $n$-decane onto the Pt/Al-SBA-15 and Pt/ZSC catalysts.

Table 2. Gas product analysis for $\mathrm{n}$-decane hydrocracking on Pt/ZSC catalyst (WHSV =

$$
5.2 \mathrm{~h}^{-1}, \mathrm{H}_{2} / \mathrm{n}-\mathrm{C}_{10}=9, \mathrm{P}=40 \mathrm{bar} \text { ) }
$$

\begin{tabular}{lcccc}
\hline Temp. $\left({ }^{\circ} \mathrm{C}\right)$ & 250 & 275 & 300 & 325 \\
\hline n-decane conversion (\%) & 28.34 & 63.79 & 98.00 & 100.00 \\
\hline Cracking selectivity (\%) & 92.90 & 93.77 & 99.05 & 100.00 \\
\hline C1 & 0.078 & 0 & 0 & 0.07 \\
C2 & 0 & 0.07 & 0.14 & 0.43 \\
C3 & 17.7 & 19.4 & 19.4 & 23.2 \\
i-C4 & 10.6 & 12.9 & 14.6 & 17.2 \\
n-C4 & 14.4 & 15.1 & 14.5 & 16.1 \\
i-c5 & 6.2 & 7.9 & 9.3 & 11.2 \\
n-c5 & 14.5 & 14.3 & 13.7 & 12.1 \\
C5 $=$ & 4.32 & 0.002 & 0.001 & 0.001 \\
C6+ & 31.83 & 29.857 & 27.89 & 19.37 \\
unknown & 0.372 & 0.471 & 0.469 & 0.329
\end{tabular}


Table 3. Gas product analysis of the n-decane hydrocracking on Pt/Al-SBA-15 catalyst

$$
\left(\mathrm{WHSV}=5.2 \mathrm{~h}^{-1}, \mathrm{H}_{2} / \mathrm{n}-\mathrm{C}_{10}=9, \mathrm{P}=40 \mathrm{bar}\right)
$$

\begin{tabular}{lccc}
\hline Temp. $\left({ }^{\circ} \mathrm{C}\right)$ & 300 & 325 & 350 \\
\hline n-decane conversion (\%) & 20.92 & 61.85 & 93.67 \\
\hline Cracking selectivity (\%) & 5.37 & 36.91 & 75.46 \\
\hline $\mathrm{C} 1$ & 0 & 0 & 0 \\
$\mathrm{C} 2$ & 0 & 0 & 0 \\
$\mathrm{C} 3$ & 19.20 & 18.90 & 18.60 \\
i-C4 & 9.40 & 9.36 & 9.20 \\
n-C4 & 10.60 & 11.80 & 12.50 \\
i-c5 & 7.90 & 7.64 & 7.30 \\
n-c5 & 9.40 & 9.69 & 10.10 \\
C5 & & 0.01 & 0.01 \\
C6+ & 0.01 & 42.37 & 42.09 \\
unknown & 43.28 & 0.23 & 0.20 \\
total & 0.21 & 100 & 100
\end{tabular}

Very small amounts of methane and ethane were also found in the hydrocracking gas phase products on Pt/ZSC catalyst. According to reports of Elangovan and Hartmann, the presence of such molecules might be an indication of an ionic mechanism of cleavage under the hydrocracking conditions [6]. At low temperatures, very small amounts of $\mathrm{C}^{=}$ were also detected and could be explained by an inefficient hydrogenation capacity at this temperature. 
Figure 7 depicts the influence of the $\mathrm{H}_{2}$ /feed molar ratio on the catalytic activity of $\mathrm{Pt} / \mathrm{ZSC}$ for $n$-decane hydrocracking and the evolution of the conversion in time. The collected results demonstrated that an increase of this ratio led to the decrease of the conversion because of the lower partial pressure of n-decane. More important is the evolution of the conversion in time, where the results showed that on Pt/ZSC no fast deactivation occurred. Such a behavior may indeed recommend this support for the production of catalysts for hydrocracking.
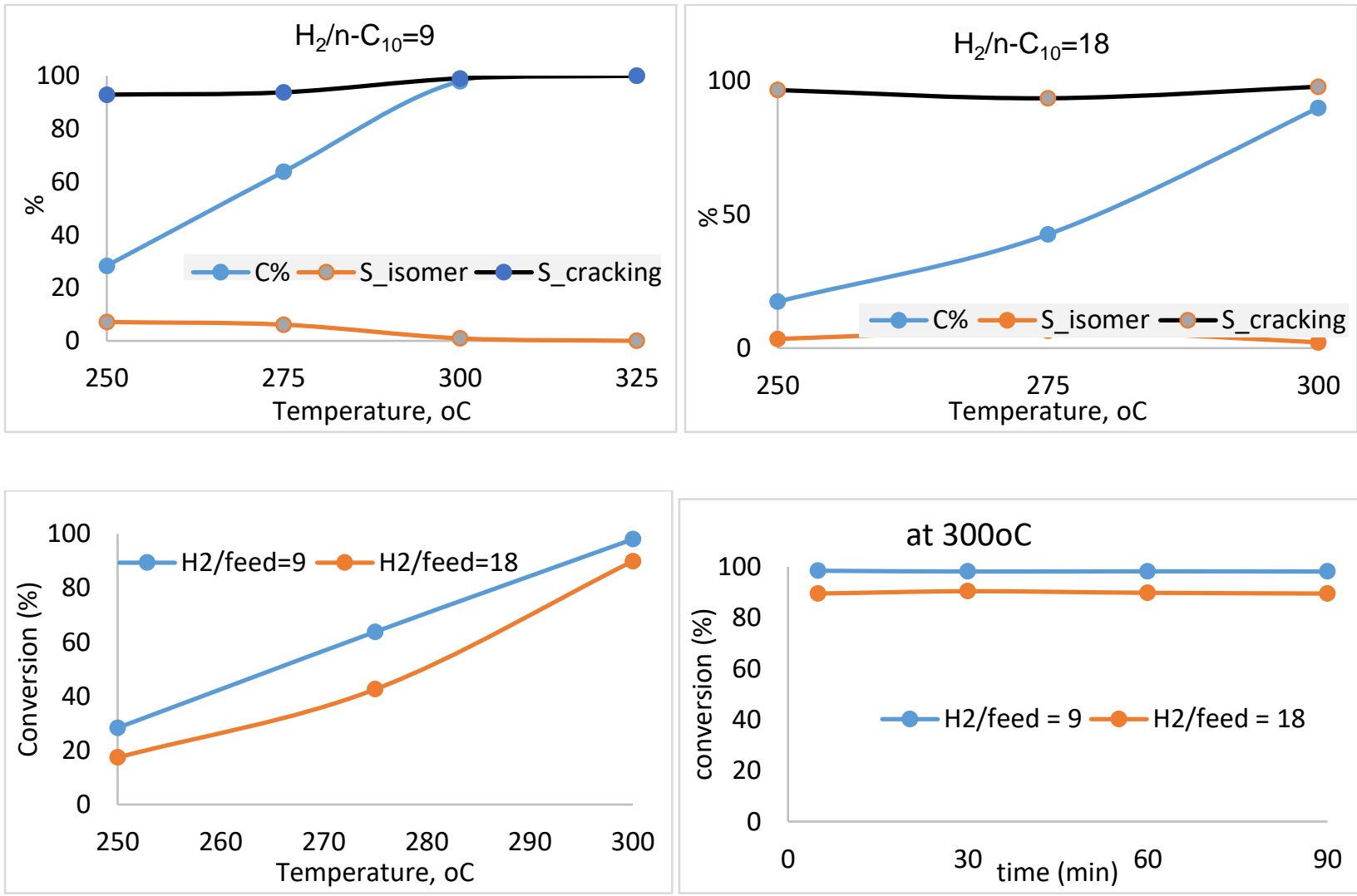

Fig.7. Influence of temperature and time for $n$-decane hydrocracking of Pt/ZSC at different $\mathrm{H}_{2} / n$-decane molar ratios $\left(\mathrm{WHSV}=5.2 \mathrm{~h}^{-1}, \mathrm{P}=40 \mathrm{bar}\right.$ )

\section{Conclusions}

The composite ZSC support prepared in this study can be synthesized following a simple and reproducible procedure. Its characterization demonstrated a trimodal pore size 
distribution in which the walls formed from microporous ZSM-5 generated a bimodal mesoporous texture. Py-FTIR measurements showed that this material exhibits acidic properties where the Brønsted acid site density is larger than that in Pt/Al-SBA-15. For the Al-SBA-15 dominated the Lewis acidity. The deposition of Pt on this support occurred in a less uniform shape as for Al-SBA-15.

The evaluation of the catalytic activity in the hydrocracking of $n$-decane demonstrated that both the conversion and the selectivity depended on the acidity and the pore size of the catalyst. A higher Brønsted acidity coupled to the existence of the zeolitic mesopore walls afforded good catalyst performances for hydrocracking. Oppositely, Pt/Al-SBA-15 was found as a suitable catalyst for hydroisomerization. The homogeneity of Pt particles on the support appeared as being less important in this stage. Such a behavior may indeed recommend the ZSC support as suitable for the synthesis of catalysts for hydrocracking.

Acknowledgement: This research is funded by Vietnam National Foundation for Science and Technology Development (NAFOSTED) under grant number 104.05-2014.21

\section{References}

1. W. Vermeiren, J.-P. Gilson, Top. Catal. 52 (2009)1131-1161.

2. A. Corma, A. Martinez, S. Pergher, S. Peratello, C. Perego, G. Bellusi, Appl. Catal. A 152 (1997) 107-125.

3. V. Calemma, S. Peratello, C. Perego, Appl. Catal. A 190 (2000) 207-218.

4. R. Sahu, B. J. Song, J.S. Im, Y-P. Jeon, C.W. Lee, J. Ind. Eng. Chem. 27 (2015) 12-24.

5. C. Martínez, A.Corma, Coord. Chem. Rev. 255 (2011) 1558-1580.

6. S.P. Elangovan, M. Hartmann, J. Catal. 217 (2003) 388-395.

7. H. Deldari, Appl. Catal. A: General 293 (2005) 1-10. 
8. R. Kenmogne, A. Finiels, C. Cammarano, V. Hulea, F. Fajula, J. Catal. 329 (2015) 348354.

9. A. Martínez, M.A. Arribas, M. Derewinski, A. Burkat-Dulak, Appl. Catal. A: General 379 (2010) 188-197.

10. S. Fernandes, M. Andrade, C. O. Ania, A. Martins, J. Pires, A. P. Carvalho, Micropor. Mesopor. Mater. 163 (2012) 21-28.

11. M. Guisnet, Catal. Today 218-219 (2013) 123-134.

12. E. Verheyen, C. Jo, M. Kurttepeli, G. Vanbutsele, E. Gobechiya, T. I. Korányi, S. Bals, G. V. Tendeloo, R. Ryoo, C. E.A. Kirschhock, J. A. Martens, J. Catal. 300 (2013) 70-80.

13. J. A. Martens, D.Verboekend, K. Thomas, G.Vanbutsele, J. P.-Ramírez, J.-P. Gilson, Catal. Today 218-219 (2013) 135-142.

14. N. Kasian, E. Verheyen, G. Vanbutsele, K. Houthoofd, T. I. Koranyi, J. A. Martens, C. E.A. Kirschhock, Micropor. Mesopor. Mater. 166 (2013) 153-160.

15. B.C. Gagea, Y. Lorgouilloux, Y. Altintas, P.A. Jacobs, J.A. Martens, J. Catal. 265 (2009) 99-108.

16. D. T. On, S. Kaliaguine, Angew. Chem. 113 (2001) 3348-3351.

17. L.T.H. Nam, T.Q Vinh, N.D Hoa, M. Hunger, Int. J. Nanotechnol., 12 (2015) 466-474.

18. P.T. Huyen, M. Krivec, M. Kočevar, I. C. Bucur, C. Rizescu, V. I. Parvulescu, ChemCatChem, 2016, 8, 1-12.

19. S. Handjani, S. Dzwigaj, J. Blanchard, E. Marceau, J-.M. Krafft, M. Che, Top. Catal. 52 (2009) 334-343.

20. Y. Rezgui, M. Guemini, Appl. Catal. A: General 282 (2005) 45-53. 